\title{
The French-Farsi Simultaneous Early Bilingualism in an Iranian Child - Study on the Regularity of the Presence of the Minority Language in the First Lexical Productions of a Bilingual Child
}

\author{
Sahar Jalilian ${ }^{1}$, Rouhollah Rahmatian ${ }^{1}$, Parivash Safa $^{1} \&$ Roya Letafati ${ }^{1}$ \\ ${ }^{1}$ French Education Department, Faculty of Humanities, Tarbiat Modares University, Iran \\ Correspondence: Rouhollah Rahmatian, Associate Professor, French Education Department, Faculty of \\ Humanities, Tarbiat Modares University, P. O. Box 14115-111, Tehran, Iran. Tel: 98-91-2315-0345. E-mail: \\ rahmatir@modares.ac.ir
}

Received: August 6, 2016

doi:10.5539/ies.v10n2p156
Accepted: September 12, $2016 \quad$ Online Published: January 30, 2017

URL: http://dx.doi.org/10.5539/ies.v10n2p156

\begin{abstract}
In a simultaneous bilingual education, there are many factors that can affect its success, primarily the age of the child and socio-cognitive elements. This phenomenon can be initially studied in the first lexical productions of either language in a child. The present study focuses on the early lexical developments of a child, who lives in the monolingual society of Iran, where there is no linguistic milieu for French, and has been exposed to a bilingual education since birth. Applying Ronjat's principle of "one parent-one language" (1913), the parents have formed the child's basic linguistic interactions; the father employs Farsi in his interactions with the child as his mother tongue while the mother uses French as her foreign language. The data is collected from audio files recorded in the period between 18 and 36 months old of the child, containing her everyday interactions with her parents. Through the analysis of the data with the purpose of studying the changes of the presence of the minority language words, i.e. French, in the child's sentences at different ages, questions are raised regarding the conditions of a persistent presence of both languages and the reason due to which one language positions as a minor means of communication, observing parental attitudes and environmental issues that can influence the language acquisition procedure.
\end{abstract}

Keywords: early bilingualism, lexical development, minority language, principle of "one parent-one language"

\section{Introduction}

\subsection{Introduction to the Problem}

As a phenomenon that occurs through communication, language acquisition contains sociolinguistic and socio-cognitive processes as well as acquiring lexical and structural systems of a language. According to conducted researches, more than half of the world population is bilingual or multilingual and live in multilingual environments. Bilingualism is a family, social, and cultural phenomenon since it engages a position in families and societies. This study investigates the kind of bilingualism which concerns child's linguistic developments in pre-school ages, called "early bilingualism", from various aspects. Provided that two languages are acquired simultaneously or with a short gap, the phenomenon is called "early simultaneous bilingualism". Padilla and Lindholm (1984) define simultaneous bilingualism as bilingualism where the acquisition begins from the birth of a child while McLaughlin (1984) believes that any point before the age of three years old would qualify as the acquisition starting point.

"When a speaker hears and acquires at least two languages from birth on, it is referred to as simultaneous bilingualism. Whereas, sequential bilingualism occurs when the second language acquisition takes place only after the first language has been established. On condition that the acquisition of the further language takes place before puberty, it is spoken of early bilingualism." (GRIN, 2013, p: 4).

Based on the theories of Vygosky (1962), linguistic construction of each individual is not achieved without observing the interactive aspects of languages. Hence, language and cognition are two interrelated elements. It can be deduced that based on the situation in which the linguistic interactions in the surrounding environment of a child is monolingual or bilingual, the child's acquisition will be either of those. "It is important to keep in mind that context is an especially essential variable in an especially essential variable in investigating linguistic 
interactions. When examples of children's linguistic interactions are taken out of context, they lose their richness in meaning." (Lindholm \& Padilla, 1978, p. 25)

\subsection{Importance of the Problem}

Remarkable studies in bilingual development of children (Grosjean, 1982; De Houwer, 1990; Meisel, 1990; Paradis \& Genesee, 1996) are mainly dedicated to European languages and the case of children with native parents who have the tendency to transmit their language to their children. This longitudinal study presents an early bilingualism situation with non-native parents, a bilingual education based on Ronjat's "one parent-one language" principle (1913). This study focuses on bilingualism including two languages which have different and distant origins, Farsi and French. Accordingly, it is the first study which focuses on a French -Farsi bilingualism in the Iranian society. Indeed in the society where the child lives, French is entirely in minority, and in this case, the mother who takes responsibility for this bilingual education is a non- native speaker of the French language; she has learned that language as a foreign language, nonetheless having a particular passion for this language, she wished to transmit this passion to her child.

\subsection{Research Hypothesis}

The present paper is a case study research on the simultaneous acquisition of two languages, or in other words early bilingualism. The purpose of this research is to investigate the dominance degree of each language in lexical development and productions of an Iranian girl in an age period of 18 to 36 month-old. "One parent- one language" principle is the approach applied in raising this child bilingual. This method creates a condition where both languages are present in the first and immediate linguistic environment of the child. So could this principle be an effective way in creating monolingual situations? It seems that this method can improve the status of the minority language in verbal communications of the child.

"In the "one parent-one language" model in the strictest sense, means that each parent speaks only one language with the child, each parent must at some time also communicate with the other parent or with other monolingual people in the presence of the child. This means that all bilingual children have at least one parent who will occasionally function bilingually, even if the parents are each monolingual when speaking to the child" (Featherston \& Sternfeld, 2007, p. 154). Meanwhile, considering the fact that in this case, the mother is the only communicational source of the French language for the child, yet has a permanent presence and a high affective role in the child learning, would this compensate for the absence of other French users? Would only her first lexical productions contain French words as she spends her first 20 months mostly with her mom? Will she be eventually able to communicate in this language?

Since child language acquisition is a phenomenon occurring through social interactions, the status of the languages in the child's primary social environment and its effects on the linguistic developments are unquestionable. The interests of this study as the first research based on a French- Farsi bilingual acquisition in the Iranian society, is the importance given to initial family interactions that define linguistic situations of the child.

\section{Early Bilingualism}

Regarding early bilingualism, De Houwer (1990) explains the conditions of this bilingualism as follows: the child must be exposed to both languages from its birth and this exposure must be occurred evenly i.e. the child must be spoken with in both languages on a daily basis. These instructions offer the general conditions of the approach and may lead to varied outcomes depending on the existing conditions in every family.

Romaine (1990) defines infantile bilingualism based on sociolinguistic status and considers the three factors of parents' language, society's language, and strategies applied by the parents (the language(s) the child is spoken with). Döpke (1992) adds another factor to the mentioned list which is the language spoken between parents. For instance, the non-dominant language can be developed better for a child whose parents use this language in their own conversations. According to De Houwer (1990), how the linguistic zone is divided in a child's life, as well as the frequency of full or partial usage of each language in the interactions with the child, are among the factors which define the child's sociolinguistic environment. Hence, studying this type of bilingualism can only be accomplished through understanding the child's linguistic conditions.

Grosjean (1982) believes that the necessity a child feels to communicate through a given language can guarantee the consistent presence of that language in its linguistic productions. This issue is explained by De Houwer (1990) differently; she believes that in addition to the duration and frequency that a child is exposed to each language, consistency of bilingualism depends on attitudes and beliefs of his family circle and the society where he lives as well as language practices. She also believes that a positive attitude on parents' side regarding the 
usage of two languages in the family environment as well as their trust in the success of the bilingualism, can be highly effective on the process of linguistic development and consistency of the bilingualism.

\subsection{The Status of Languages and Its Effect on Bilingualism}

In early bilingualism, any child is capable of developing the pair of languages harmoniously and enjoying the consequent advantages on a cognitive ground solely when the two languages are of almost equal value and status in both social and family environments; ignoring and disvaluing one language can result in the disappearance of that language in the child's lexical system. This challenging issue may appear in children who immigrate to another country of a different language at a very young age. On their arrival, to the new country, a language with a lower social status which is not regarded as prestigious is spoken by the child. This will lead to a reduced level of usage or total (intentional) omission of all acquired language skills since their birth. This phenomenon is not limited to immigrant children and depending on living circumstances, may occur in any case of bilingualism. Whenever the presence of languages in a child's life is unequal, harmonious linguistic development will not be fulfilled. In other words, discrimination will take place between the pair of languages.

Thus, the status of any given language and the behavioral attitudes of a society affects the linguistic development order. It is worth mentioning that the positive attitude toward French language in a country like Iran, which comes from the historical and cultural background of this language in the country (Ghashmardi \& Salimikouchi, 2011), cannot guarantee the success of this bilingualism because French is a minority language in Iran and few supporting factors can be perceived in reinforcing the development of a successful French-Farsi bilingualism. In the following part, the modifying factors in early bilingualism, which are associated with environmental and non-environmental elements, are studied.

\subsection{Child's Sociolinguistic Environment}

As aforementioned, society can indirectly influence early bilingualism since a child's linguistic production abilities are affected by social conditions in accepting a language. Society can affect the language practices of parents as well; for instance, if the status of a language weakens in the productions of a child owing to sociolinguistic conditions, a counteractive shift in parents' linguistic behaviors can elevate the application of non-dominant language in the child's linguistic productions. The significance of this phenomenon is more feasible in monolingual societies because in bilingual societies child's linguistic developments occur more naturally, without any special measure on parents' side. The reason is that in these societies the presence of bilingual educational facilities as well as monolingual ones and native speakers ease the process of a child's early bilingualism.

\subsection{Bilingualism in Family Environment}

Bilingualism can exist in different forms in family environment. The commonest form is a situation where each parent speaks in a different language to a child which is the "one parent- one language" principle. In this situation, the language parents use to communicate with each other is of high significance; if they use the dominant language in their society, this language becomes dominant in the child's productions and the second language, which is in minority, will be nearly excluded. This dominance can have other consequences as well; the child is inclined to use the majority language in his productions and gradually even his conversation with the non-dominant language-speaking parent will be in the dominant language.

\subsection{Inter-Linguistic Phenomenon}

Researches have indicated that inter-linguistic phenomenon is considered as a reason to reject family bilingualism and basically early bilingualism. However, several studies indicate that these phenomena gradually cease to exist as a child grows. Note that these phenomena vary from one child to another due to various reasons such as acquisition strategies, dominance of one language over another, preference of one language to another. Also, these phenomena are basically noticed in the linguistic productions of a bilingual child when they are applying the non-dominant language. "It is well established that one of the most detrimental effects of bilingualism is the potential inter-linguistic interference, resulting in decreased language performance. Interference is clearly inversely related with the similarity existing between both languages" (Ardila \& Ramos, 2007, p. 227).

In the present study, Elena's linguistic environment almost followed this process: her parents followed the above mentioned rule and her mother has been her minority language source. The absence of French language in the country of her residence has expectedly encouraged her to use the dominant language-Farsi. Under such circumstance, the parents wonder how to encourage their child to use the non-dominated language without forcing her. Children who do not use the non-dominant language in their productions, will have solely a passive 
skill in that language, i.e. they can understand the non-dominant language but they do not use it in their speaking because simply they do not practice using it and they become just a "receptive bilingual". This bilingualism is called "passive bilingualism". According to Steiner and Hyes (2009), passive bilingualism is the ability to understand a language without speaking it. The question asked is whether the input of the minority language by one parent can result in "active bilingualism" or not.

\section{Method}

This section attempts to introduce the child under study as well as the conditions governing her bilingualism training. The child of this study, Elena, has been exposed to both languages-Farsi and French- since her birth, therefore the bilingualism type is categorized under early bilingualism. Both her parents are Iranian ergo all conversations between them are in their mother tongue, Farsi. Additionally, she has been attending a day nursery from the age of 20 months old where all verbal interactions occur in Farsi. Considering the very fact that the language of Farsi is the dominant language of the child's environment, it appears that the fulfillment of bilingualism is challenging.

\subsection{The Status of French Language in the Iranian Society}

The present research is a case study of early bilingualism in Iran, a country which has one official language-Farsi. She resides in Iran and city of Tehran, a monolingual society where verbal interactions generally occur in Farsi. The status of a second language is not steady due to cultural situations and common stereotypes and depends on various factors and conditions which are not the subject of this research. The purpose is however to introduce and investigate bilingualism conditions and the French as the second language is an international language with a culturally prestigious status, a position that is not ascribed to many other languages.

The linguistic inputs in the living environment of the child result in the formation of language knowledge. "Researchers working within empiricist and social-interactionist perspectives tend to portray input as something external to the learner that is out there in the environment" (Montrul, 2008, p. 269). These inputs are not limited to words and phrases directly addressed to the child but involve any linguistic interaction taking place in the surroundings of the child including the inter-parental conversations in the presence of the child.

\subsection{Parents' Attitudes and the Status of French in the Family Environment}

In a family where either of the parents or both of them are native speakers of a language, bilingualism develops naturally since there exist a number of elements which facilitate the process such as daily interactions with the speakers of that language and visiting relatives who speak the language. "While this situation may be rare, it is not unheard of. In this scenario, both parents are native speakers of the non-dominant language. However, one of the parents addresses the child in a non-native language (that is not culturally dominant)" (Field, 2011, p. 58). Under such circumstances, the child is raised in a monolingual society and one single language is the means of communication for the parents' as well as the society's daily interactions, hence, the parent who speaks the minority language which is not necessarily their mother tongue, becomes the child's only linguistic source.

This is also the case in the present research. Elena's mother began learning French as a foreign language in the academic environment of university. Since she has been keen on learning this language and well aware of the importance of age in the process of learning a language, she decided to arrange a bilingual environment for her daughter since her birth. She had been so determined in her goal that she tried to familiarize her daughter with the language from the last months of her pregnancy by singing French songs and lullabies so that the baby would be pacified by hearing them after her birth. "If parents sing lullabies for their children, making communication a bedtime custom is also good. A music box can also serve as a substitute when parents are busy, but the lullaby of a mother or father is more intimate to a child" (Oketani-Lobbezoo, 2006, p. 112). Despite a number of obstacles and challenges, this decision was eventually executed.

The parents are well conscious that Elena is deprived of the ideal condition of experiencing a bilingual environment. Since Elena's mother is not considered a native speaker of French, this leads to limitations and challenges in raising the child bilingual. This challenging situation induces the mother to seek a solution to this issue. The first method employed is "one parent-one language" principle which was observed from the very beginning. The considerable assistance here is the supportive role of the father; though not able to speak any languages but Farsi, he demonstrates a positive attitude toward using French in the family environment and constantly supports the child's linguistic productions. What follows, discusses Elena's linguistic developments in her first stages of lexical productions, ages 18 to 36 month-old.

\subsection{Sampling Procedure \& Research Design}

The nineteen monthly recorded sessions, each 20-30 minutes, provide the required data for analysis and contain 
the child's productions between 18 to 36 months old which include her everyday interactions with her parents in both languages, mainly dyadic interactions between Elena and her mother. The child has had less interactions with her father due to his professional occupations outside home, accordingly, the presence of father during these recordings is limited to the first five records (18-22 months) and primarily the first three months and then three short telephone conversations during recordings within these three following months: 28, 31, and 34 months old. Father is the speaker of the dominant language and as we will see, his less frequent presence is significant in the results obtained.

The child spends most of her first months' after birth at home and with her mother; it is obvious that French was in majority during this period and therefore the mother-researcher had the idea that these dyadic interactions would suffice for the process of bilingual development. However, as time went forward and Elena's social relations widened, external factors, among which her presence at the day nursery from the age of 20 months old as the most significant, began influencing her bilingual process. Her mother's efforts to incorporate French in the outside environment were in vain since French is not a common language in the Iranian pre-school educational system where English is the second/ foreign official language. Centers with French as their prior language are limited in number and are not in sync with employed mothers' working hours. Hence, after entering day nursery, Farsi gradually solidified its place as the child's main language. As mentioned earlier, the majority of the data of this study includes the recorded everyday interactions between the child and her parents between the ages of 18 and 36 month-old, from June 2014 to December 2015.

\section{Results}

Total statements produced by Elena and her parents in their everyday interactions, in number and percentage, during the recorded sessions to clarify the status of each language in their productions are indicated in Table 1. By "mixed statement", we mean that this is a statement formed from a combination of Farsi and French words.

Table 1. Nature and percentage of statements produced by speakers

\begin{tabular}{|c|c|c|c|c|c|c|c|}
\hline \multirow{2}{*}{ Speaker } & \multirow{2}{*}{$\begin{array}{c}\text { Total } \\
\text { statements }\end{array}$} & \multicolumn{2}{|c|}{ French statements } & \multicolumn{2}{|c|}{ Farsi statements } & \multicolumn{2}{|c|}{ Mixed statements } \\
\hline & & number & percentage & Number & percentage & Number & Percentage \\
\hline Mother & 1492 & 1438 & $96.3 \%$ & 46 & $3.08 \%$ & 8 & $0.5 \%$ \\
\hline Father & 167 & 19 & $11.3 \%$ & 138 & $82.6 \%$ & 10 & $5.9 \%$ \\
\hline Child & 1241 & 630 & $51 \%$ & 386 & $31 \%$ & 230 & $18 \%$ \\
\hline
\end{tabular}

The noteworthy point in here is the number of French statements being produced by each of them. Since the "one parent-one language" principle has been fully observed, her mother's statements, when addressing Elena, have been in French while the Farsi statements as well as mixed ones have been only used to interact with the father while Elena is present in the environment. The other point which can be noticed is the low number of statements produced by the father. Due to work matters, the father managed to participate only in 5 recording sessions. His French proficiency is at a basic level however due to the repetition of a number of words and phrases in the interactions between Elena and her mother, the father is capable of comprehending as well as employing these words and phrases. This situation can explain the presence of mixed statements in the father's linguistic productions. The reason being that due to his working hours, the father could be present in a few sessions. It is worth mentioning that the stated premise has also been true during the time that the child is engaged with her other activities and thus the mother has been her main and only companion at home.

As we see in diagram 1, during the months of data recording, the presence of Elena's mother is stronger than the father's, thus it is obvious that Elena's linguistic input is mostly provided by her mother and her family environment is majorly dedicated to mother-child dyadic interactions which include the mother addressing Elena in French.. It should be noted that the aforementioned situation is still present as this study is being put into words. 


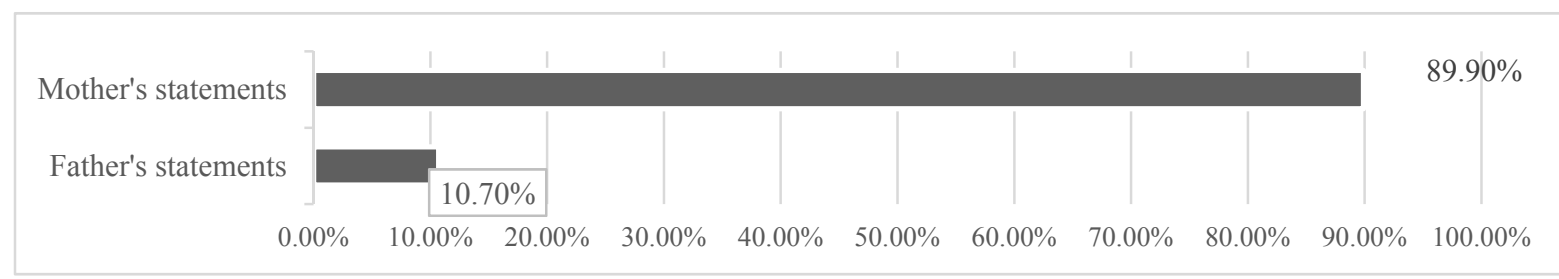

Diagram1. The participation percentage of the mother and father in producing statements

The child lives in a monolingual society where social interactions are in Farsi; the father speaks to her in Farsi and this language in the only one she hears in the environment of her nursery. Due to this constant presence of Farsi, the child's linguistic productions do not necessarily occur in French even when she speaks to her mother.

\subsection{Statement Analysis Method}

In this part, the process of the dominance of one language is introduced and discussed. The method applied is based on a research conducted by Ghimenton (2008). She has studied and analyzed the words and phrases produced by an Italian-Provencal child to compare the number of words produced in Italian and Provencal Dialect in a period of 14 months. The present study has applied the same method to study the words produced by Elena.

As mentioned above, Elena's sentences can be categorized as French, Farsi, and mixed. All the words in a French sentence are of this language and therefore the sentence is of French nature. The same applies to a Farsi sentence with Farsi words and nature. However, a mixed sentence has the nature of both Farsi and French words. The following diagram is an example of the method applied in order to identify the type of words and the percentage of their presence in each sentence produced by Elena. The Table 2 analyzes a mixed statement consisting the words of the pair of languages.

Table 2. Single statement analysis method

\begin{tabular}{lccccc}
\hline & \multicolumn{4}{c}{ a 5-word statement } \\
\hline Number of words & Word 1 & Word 2 & Word 3 & Word 4 & Word 5 \\
Nature of words & French & French & French & Farsi & Farsi \\
Fraction of words & & 3 out of 5 & & 2 out of 5 \\
Percentage of words & & $60 \%$ & & $40 \%$ \\
\hline
\end{tabular}

Each recorded session consists of several statements and in view of that, each session needed to be calculated. Table 3 is an example to describe the method through which the nature of the words forming a statement produced by Elena in one session is analyzed. In this study, single words are excluded and solely the words forming a statement are investigated.

Table 3. Session statement analysis method

\begin{tabular}{|c|c|c|c|c|c|}
\hline \multirow{2}{*}{ Statements } & \multirow{2}{*}{ Number of words in each statement } & \multicolumn{2}{|c|}{ Nature of words } & \multicolumn{2}{|c|}{ Percentage } \\
\hline & & French & Farsi & French & Farsi \\
\hline A & 4 & 2 & 2 & $50 \%$ & $50 \%$ \\
\hline B & 5 & 1 & 4 & $20 \%$ & $80 \%$ \\
\hline $\mathrm{C}$ & 3 & 2 & 1 & $66.6 \%$ & $33.3 \%$ \\
\hline $\mathrm{D}$ & 6 & 1 & 5 & $16.6 \%$ & $83.3 \%$ \\
\hline $\mathrm{E}$ & 2 & 2 & 0 & $100 \%$ & $0.0 \%$ \\
\hline Total number of statements: 5 & & & & $50.64 \%$ & $49.32 \%$ \\
\hline
\end{tabular}

\subsection{Statistics and Data Analysis}

Once the method of analysis is clarified, sessions' statements are analyzed accordingly. Table 4 determines the priority of each language according to the age of the child by demonstrating the percentage of the nature of words in each sentence, collected from the sessions recorded between the ages of 18 and 36 months old of the 
child.

Table 4. The average percentage of the type of the words in the child's statements based on her age

\begin{tabular}{cccc}
\hline \multirow{2}{*}{$\begin{array}{c}\text { The child's age (in } \\
\text { month) }\end{array}$} & Number of statements & Mean percentage of the words types present in the child's statements based on her age \\
\cline { 2 - 4 } 18 & 13 & French & Farsi \\
\hline 19 & 32 & $38.46 \%$ & $61.53 \%$ \\
20 & 24 & $46.35 \%$ & $53.64 \%$ \\
21 & 101 & $54.16 \%$ & $45.83 \%$ \\
22 & 66 & $89.52 \%$ & $10.47 \%$ \\
23 & 83 & $75.75 \%$ & $24.24 \%$ \\
24 & 46 & $89.52 \%$ & $10.28 \%$ \\
25 & 60 & $80.25 \%$ & $19.74 \%$ \\
26 & 84 & $51.73 \%$ & $47.67 \%$ \\
27 & 135 & $61.97 \%$ & $38.00 \%$ \\
28 & 35 & $37.72 \%$ & $67.49 \%$ \\
29 & 75 & $54.76 \%$ & $45.23 \%$ \\
30 & 41 & $74.39 \%$ & $25.59 \%$ \\
31 & 80 & $80.08 \%$ & $19.91 \%$ \\
32 & 55 & $64.57 \%$ & $34.78 \%$ \\
33 & 94 & $72.93 \%$ & $27.05 \%$ \\
34 & 62 & $31.07 \%$ & $68.91 \%$ \\
35 & 138 & $52.28 \%$ & $47.71 \%$ \\
36 & 37 & $40.62 \%$ & $59.26 \%$ \\
& & $62.83 \%$ & $37.15 \%$ \\
\hline
\end{tabular}

As demonstrated above, French has been in priority in Elena's lexical production throughout her dyadic and triadic interactions with her parents and it can be understood from the analysis of the Table 4 that French is the language of Elena's home environment throughout the months when the study had been conducted. However, after the child enters the outside social life, the priority shifts gradually from French to Farsi during the last months of this study. In order to have a better understanding of the data, diagrammatic presentation of Table 4 is presented.

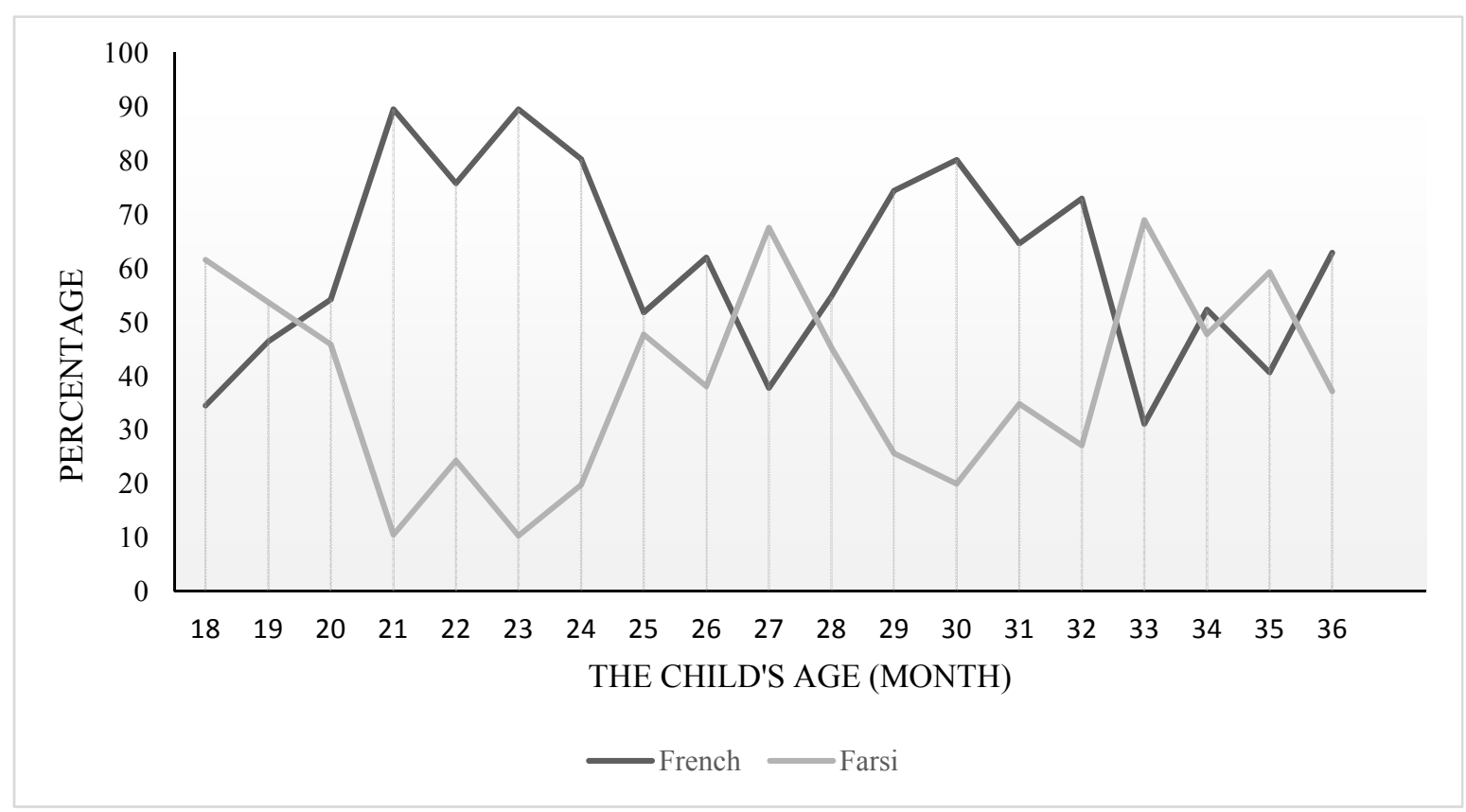

Diagram 2. Presence of languages in the child's production 


\section{Discussion}

Elena's lexical development can be assessed in several sections, depending on her linguistic environment, her own and her parents' attitudes.

18-20 months: Regarding the fact that at this age, Elena's linguistic environment occurs mainly by her parents and her family and since her mother was much more present than his father, the very early stages of dyadic productions between mother and daughter were happening in French; in the triadic interactions however, Elena reveals to be more likely to speak Farsi because she knows that her words are understandable to both parents. The three sessions recorded primarily include its triadic interactions.

21-24 months: The beginning of attending the nursery on a regular basis, five days a week and 7 hours per day. This is an excellent opportunity to further practice Farsi. The mother-researcher observing the situation, notes that the status of the French language is becoming quite unstable, so she tries to enrich verbal exchanges by creating playful moments for the child; educational French rhymes find essentially a place in the daily life of the child and these three months show the effects of these dyadic monolingual activities.

25-28 months: Despite maternal attitudes that carry the particular trend in the minority language, Elena is well accustomed to the nursery and is impressed with the entertaining activities in company of other children of her age; the results show a lexical explosion in Farsi; extra educational tools for French were also stopped, it was remarkable that the competence of Elena in French lessens towards a passive skill, she understands her mother's words but she responds in Farsi.

33-36 months: Exchanges during the day with the mother and thus with French is reduced and Elena who spends half of her day at the nursery is making progress in the dominant language. So during these months, Farsi begins to manifest itself in Elena's productions. It should be added that since her birth, the mother attentively practices the rule of "one parent-one language"; the instability of the place of the French language in the child's productions, raises doubts on the effectiveness of this method for the development of children's active bilingualism.

Observing and monitoring this issue, the mother-researcher realizes that the sheer dependence on "one parentone language" principle is not adequate to develop the child's bilingualism since this principle, though facilitating the child's comprehension competence, does not exclusively assist the equal progress of lexical and linguistic productions of the child. Hence, supplementary strategies ought to be applied to sustain the status of French as part of the child bilingualism by increasing its application in the child's linguistic interactions. Though depending on mother as the only communicational source of French could make the minority language progress yet the child still needs more situations to hear French; considering this fact, this non-dominant language should become language of the playful and entertaining moments of Elena in her dyadic conversations with her mother.

\section{Conclusion}

This study has focused on an early bilingual case, following the "one parent-one language" in the child's linguistic process since her birth that leads to constant presence of French in her linguistic environment. Language acquisition process of this bilingual child considering parents' linguistic inputs and the child's outputs has been investigated. Considering that environmental factors commonly place one language in a minority position, studies on early bilingualism individual cases, have spoken of promoting elements such as meeting a family member or being cared of by a baby sitter who speaks that language, or attending schools, spending long stays or traveling to the country where that language is spoken. The child in the present study, unlike these studies, has been deprived of these facilitating occasions and in this view, the present research is novel. In this study, the nature of the linguistic inputs and specifically that of the mother's, as the only source of one language, has been examined in view of the linguistic environment of the family.

By analyzing the first stages of simultaneous Farsi and French acquisition of the child with monolingual parents in a Farsi speaking social environment, it could be understood that though language acquisition is a social process, it mainly starts in the interactions between a child and an adult that lead to the internalization of the child's linguistic skills. Consequently, bilingualism under such circumstances is possible but usually results in dominant bilingualism. Thus, strategies must be considered to improve the child's skills in producing the minority language to sustain a bilingual harmonized rhythm and avoid passive bilingualism. This purpose will not be fulfilled unless a demand to interact in the minority language is created meaning that the interactions with the child must be made in this language to enable the child to develop his linguistic capacities through an increased level of its application. Learning planning and application of educational tools is a must in order to maintain a regular language usage in the child's daily activities, for instance using story books in the minority 
language ought to be a part of daily activities and one to two hours ought to be dedicated to watching TV programs in that language accompanied by interactive activities that can promote an opportunity which may eventually develop the child's oral language.

An important point which must be observed in a bilingual education is the position of the parent speaking the minority language. In this case study, both parents have a positive attitude toward their child's bilingualism which has been encouraging for the child. The parent's consciousness of their important role in their child's success in language acquisition is crucial since they must be well aware that the child's linguistics inputs of the minority language is only provided by them and this must give them determination to place their commitment in providing a richer educational planning during the linguistic development stages of the child. Therefore, there exists a close relation between the consistence of bilingualism and the educational planning focusing on the minority language by the parent.

\section{References}

Ardila, A., \& Ramos, E. (2007) Speech and Language Disorders in Bilinguals. New York, NY: Nova Publishers.

Auer, P., \& Wei. Li. (2007). Handbook of multilingualism and multilingual communication. Berlin, Mouton de Gruyter publishing, Berlin. https://doi.org/10.1515/9783110198553

Cenoz, J., \& Genesee, F. (2001) Trends in Bilingual Acquisition. The Netherlands, Amsterdam: John Benjamins Publishing Company. https://doi.org/10.1075/tilar.1

De Houwer, A. (1990). The Acquisition of Two Languages from Birth: A Case Study. Cambridge: Cambridge University Press. https://doi.org/10.1017/CBO9780511519789

Döpke, S. (1998). The Role of Parental Teaching Techniques in Bilingual German-English Families. International Journal of the Sociology of Language, 72, 101-112. http://dx.doi.org/10.1515/ijsl.1988.72.101

Festherston, S., \& Sternefeld, W. (2007). Roots: Linguistics in search of its evidential base. Studies in Generative Grammar, 96. Berlin: Walter de Gruyter.

Field, F. (2011). Bilingualism in the USA: The case of the Chicano-Latino Community. The Netherlands, Amsterdam: John Benjamins Publishing Company. https://doi.org/10.1075/sibil.44

Gashmardi, M. R., \& Salimikouchi, E. (2011). Parcours de la francophonie en Iran: Une francophonie latente. Alternative Francophone, 1(4), 99-112. http://ejournals.library.ualberta.ca/index.php/af

Ghimenton, A. (2008) Acquisition plurilingue chez un jeune enfant de Vénétie: Etude de la fréquence d'usage des langues et des indices pragmatiques lors des interactions familiales. Linguistique. Université Stendhal-Grenoble III.

Grin, V. (2013). The role of age in second language acquisition. 18 pages, Seminar paper from the year 2012 in the subject English-Pedagogy, Didactics, Literature Studies, grade: 1, 3, Ernst Moritz Arndt University of Greifswald, course: Aspects of bilingualism, language.

Grosjean, F. (1982). Life with two languages: An introduction to bilingualism. Cambridge (Mass.): Harvard University Press.

Lindholm, K. J., \& Padilla, A. M. (1976), Linguistic Interaction in Bilingual Children. Spanish Speaking Mental Health Research Center.

McLaughlin, B. (1984). Second-Language Acquisition in Childhood. Vol. 1, Preschool children. Hillsdale, NJ: Erlbaum.

Montrul, S. (2008). Incomplete Acquisition in Bilingualism: Re-examining the Age Factor. The Netherlands, Amsterdam: John Benjamins Publishing Company. https://doi.org/10.1075/sibil.39

Oketani-Lobbezoo, H. (2006). Raising children as bilingual: bilingual education from age zero. Michigan, Ypsilanti: Eastern Michigan University Publications.

Padilla, A. M., \& Lindholm, K. J. (1984). Child bilingualism: The same old issues revisited. In J. L. Martinez, \& R. H. Mendoza (Eds.), Chicano Psychology. New York: Academic Press. https://doi.org/10.1016/B978-0-12-475660-1.50023-1

Romaine, S. (1994). Bilingualism. Oxford: Blackwell Publishers.

Ronjat, J. (1913). Le Développement du Langage Observé Chez un Enfant Bilingue. Paris: Champion. https://ia802704.us.archive.org/0/items/ledveloppement00ronjuoft/ledveloppement00ronjuoft_bw.pdf 
Steiner, N., \& Hyes, S. L. (2009). 7 Steps to Raising a Bilingual Child. New York: AMACOM

Vygotsky, L. S. (1962). Thought and language. Cambridge, MA: MIT Press. https://doi.org/10.1037/11193-000

\section{Copyrights}

Copyright for this article is retained by the author(s), with first publication rights granted to the journal.

This is an open-access article distributed under the terms and conditions of the Creative Commons Attribution license (http://creativecommons.org/licenses/by/4.0/). 